\title{
Serum Telomerase Levels and COPD Exacerbations
}

\author{
Fulsen Bozkus MD, Selma Guler MD, and Secıl Simsek MD
}

\begin{abstract}
BACKGROUND: To our knowledge, there is no study on the level of telomerase in subjects with COPD during an exacerbation period. The objective of this work was to compare lipid peroxidation, telomerase, zinc $(\mathrm{Zn})$, copper $(\mathrm{Cu})$, and malondialdehyde levels in asymptomatic smokers and subjects with COPD exacerbation. METHODS: The study included 45 subjects with COPD exacerbation and 42 healthy subjects with tobacco use as a control group. Samples were taken from blood and after the serum levels of telomerase malondialdehyde, $\mathrm{Cu}$, and $\mathrm{Zn}$ were measured, the values were compared between the 2 groups. Tests for respiratory function were performed, and sedimentation and C-reactive protein levels were measured. RESULTS: The COPD exacerbation group had a significantly $(P<.001)$ lower $\mathrm{Cu} / \mathrm{Zn}$ ratio compared with the control group; however, the COPD exacerbation group had significantly $(P<.001)$ higher levels of telomerase malondialdehyde, $\mathrm{Cu}$, and $\mathrm{Zn}$ compared with the control group. Malondialdehyde, $\mathrm{Cu}, \mathrm{Zn}$, and $\mathrm{FEV}_{1}$ were found negatively correlated in the COPD exacerbation and control groups $(P<.001)$. The COPD exacerbation group had lower $\mathrm{FEV}_{1}$ and $\mathrm{FVC}$ compared with the control group. The COPD exacerbation group had significantly $(P<.001)$ higher levels of $C$-reactive protein and a higher blood cell sedimentation rate compared with the control group. CONCLUSIONS: The reason why the subjects had a reduced $\mathrm{Cu} / \mathrm{Zn}$ ratio and increased levels of telomerase, $\mathrm{Cu}$, and $\mathrm{Zn}$ is likely to be oxidative stress, which can be defined as an increased exposure to oxidants and/or decreased antioxidant capacities It is obvious from this study that lung oxidant-antioxidant balance is abnormal in subjects with COPD exacerbation and also that the increased level of telomerase is associated with this imbalance. Key words: telomerase; copper; zinc; COPD; exacerbation. [Respir Care 2016;61(3):359-365. (C) 2016 Daedalus Enterprises]
\end{abstract}

\section{Introduction}

The primary pathophysiological mechanism for COPD is chronic systemic oxidative stress. ${ }^{1}$ The impairment of

\footnotetext{
Dr Bozkus is affiliated with the Department of Chest Diseases, and Dr Guler is affiliated with the Department of Infectious Diseases, Kahramanmaras Sutcu Imam University, Kahramanmaras, Turkey. Dr Simsek is affiliated with the Department of Biochemistry, Kahramanmaras Pazarcık State Hospital, Kahramanmaras, Turkey.

Dr Bozkus presented a version of this paper at the 18th Turkish Thorax Congress, held April 1-5, 2015, in Antalya, Turkey.

The authors have disclosed no conflicts of interest.

Correspondence: Fulsen Bozkus MD, Faculty of Medicine, Sutcu Imam University, Avsar Campus, 46100 Kahramanmaras, Turkey. E-mail: fulsenbatmaz@gmail.com.
}

DOI: $10.4187 /$ respcare. 04389 air flow describes COPD, which is not fully reversible and is related to an inflammatory response of the lungs. The key cells involved in such inflammation are monocytes and macrophages. COPD is a major cause of mortality worldwide (fourth leading cause of death), and it is projected that it will rise to the third leading cause of death in 2020 due to tobacco use. This condition has different prevalence in different countries and also in different regions of countries around the world. ${ }^{2,3}$ The most significant risk factor for COPD is cigarette smoke. On the other hand, COPD occurs in few tobacco users, and this has not yet been clearly explained. ${ }^{4}$ Additionally, the oxidative stress due to a disturbance in the balance between the manifestation of reactive oxygen species and the system's ability to detoxify their harmful effects using antioxidants was associated with the progression of the disease and complications in subjects with COPD. 5

Several trace elements play significant roles in the balance between oxidants and antioxidants. In this respect, it 
is believed that trace elements are direct or indirect parts of the pathogenetic mechanisms for many diseases. ${ }^{6}$

Furthermore, chronic oxidative stress has been demonstrated to cause an increase in the telomerase loss rate in many animal and in vivo models. ${ }^{7-9}$ The telomere is a complex of DNA+ protein at the termini of linear chromosomes, which protects the chromosome and supports stabilizing the chromosome. Telomere maintenance is essential for DNA to be fully replicated because it ensures the prevention of nuclease degradation, end-to-end fusion, and cellular senescence for the chromosomes. ${ }^{10}$ Since normal cell division involves shortening of telomeres, the telomere length and telomere shortening rate are used to indicate the aging in mitotic cells. Telomerase, a cellular enzyme, inhibits the shortening of telomeres. When each somatic cell undergoes division, telomeres start to shorten, and such shortening reaching a critical length results in replicative senescence for the cells. ${ }^{11,12}$ Because the cellular telomere loss seems to result from cell division only to a partial extent, other mechanisms, especially oxidative stress, were asserted to play a role in the increased rate for shortening of telomeres. ${ }^{9,13,14}$ This observation suggests that the levels of the enzyme telomerase might actually be associated with oxidative stress, with increased oxidative stress leading to higher telomerase levels.

The experimental proof indicating that oxidative stress is a key determinant for the shortening of telomeres may lead to the assumption that it is possible to assess telomerase levels as a response to oxidative stress. To the best of our knowledge, no studies have been performed until now regarding telomerase levels in COPD exacerbation. In this context, the aim of the current study was to investigate telomerase levels in asymptomatic smokers and subjects with COPD exacerbation and to perform the necessary comparisons.

\section{Methods}

\section{Subjects}

This study, based on a prospective design, was performed between January 2014 and June 2014 at the Chest Diseases Department of the Kahramanmaras Sutcu Imam University. Forty-five subjects who presented with COPD exacerbation were included in the study. The control group included 42 healthy subjects with tobacco use, who had no medical conditions. COPD was defined according to the Global Initiative for Chronic Obstructive Lung Disease criteria. ${ }^{15}$ COPD exacerbation is defined as an event in the natural course of the disease characterized by a change in the patient's baseline dyspnea, cough, and/or sputum that is beyond normal day-to-day variations, is acute in onset, and may warrant a change in regular medication in a patient with underlying COPD. ${ }^{15}$ The criteria for COPD ex-

\section{QUICK LOOK}

\section{Current knowledge}

Oxidative stress is known as one of the main predisposing factors of COPD. Inhaled oxidants and reactive oxygen species released by inflammatory, epithelial, and immune cells of the airway cause increased oxidative stress in patients with COPD. Telomere is a complex of DNA + protein at the termini of linear chromosomes, which protects the chromosome and supports stabilizing the chromosome. Telomerase, a cellular enzyme, inhibits the shortening of telomeres. Oxidative stress also plays a role in the increased rate of shortening of telomeres. This observation suggests that increased oxidative stress leads to higher telomerase levels.

\section{What this paper contributes to our knowledge}

The present study suggests that the impaired balance between oxidants and antioxidants and the increased level of telomerase are associated. In COPD subjects, antioxidant capacity is reduced as a result of cigarette smoking. A variety of oxidants and free radicals are implicated in the pathogenesis of COPD, so a combination of antioxidants may be effective in the treatment of COPD. Antioxidant compounds may also be valuable in monitoring oxidative biomarkers indicating disease progression. However, there is still a need for clarification of whether the increased level of telomerase is a cause or a consequence of such imbalance.

acerbation are defined as follows: (1) new onset of at least 2 of the following major symptoms: dyspnea, purulent sputum, or increased sputum; (2) new onset of one of the above major symptoms and at least 2 of the following minor symptoms: upper respiratory tract infection in the past 5 days, exacerbation of dyspnea, increased breathing frequency or heart rate increase of $20 \%$ compared with baseline, exacerbation of cough, or fever; and (3) exacerbation of disease lasting $>2$ days. ${ }^{15}$

Exclusion criteria were respiratory disorders other than COPD, known psychiatric illness, maintenance treatment with systemic corticosteroids, a new radiological infiltrate, malignancy, overt cardiac failure, recent surgery, chronic autoimmune disorders, and severe endocrine, hepatic, or renal disease. Tests for respiratory function were performed according to the European Respiratory Society standards, ${ }^{16}$ with the subjects in a sitting position, by the same technician to ensure consistency of the technique. The present study was compatible with the Second Declaration of Helsinki. The Kahramanmaras Sutcu Imam University Eth- 
Table 1. Characteristics of the Study Population

\begin{tabular}{|c|c|c|c|}
\hline Characteristics & COPD Exacerbation & Control & $P$ \\
\hline $\operatorname{Sex}(\mathrm{M} / \mathrm{F}), n(\%)$ & $29 / 16(64.4 / 35.6)$ & $30 / 12(71.4 / 28.6)$ & .48 \\
\hline Age, mean \pm SD y & $61.3 \pm 4.1$ & $61.1 \pm 4.4$ & .85 \\
\hline $\mathrm{BMI}$, mean $\pm \mathrm{SD} \mathrm{kg} / \mathrm{m}^{2}$ & $25.47 \pm 0.79$ & $25.54 \pm 1.05$ & .71 \\
\hline Total smoking time, mean \pm SD pack-years & $36.51 \pm 5.19$ & $33.64 \pm 5.58$ & .002 \\
\hline $\mathrm{FEV}_{1}$, mean $\pm \mathrm{SD} \mathrm{L}$ & $0.84 \pm 0.18$ & $2.57 \pm 0.25$ & $<.001$ \\
\hline $\mathrm{FVC}$, mean $\pm \mathrm{SD} \mathrm{L}$ & $1.34 \pm 0.19$ & $2.83 \pm 0.15$ & $<.001$ \\
\hline $\mathrm{FEV}_{1} / \mathrm{FVC}$, mean $\pm \mathrm{SD}$ & $62.04 \pm 10.85$ & $90.05 \pm 10.29$ & $<.001$ \\
\hline Sedimentation, mean $\pm \mathrm{SD} \mathrm{h}$ & $32.69 \pm 3.29$ & $12.75 \pm 4.08$ & $<.001$ \\
\hline $\mathrm{CRP}$, mean $\pm \mathrm{SD} \mathrm{mg} / \mathrm{dL}$ & $31.33 \pm 5.81$ & $5.98 \pm 3.99$ & $<.001$ \\
\hline $\mathrm{MDA}$, mean $\pm \mathrm{SD} \mathrm{mM} / \mathrm{L}$ & $6.79 \pm 0.39$ & $2.41 \pm 0.28$ & $<.001$ \\
\hline Telomerase, mean $\pm \mathrm{SD} \mu \mathrm{g} / \mathrm{mL}$ & $0.42 \pm 0.05$ & $0.15 \pm 0.03$ & $<.001$ \\
\hline $\mathrm{Cu}$, mean $\pm \mathrm{SD} \mu \mathrm{g} / \mathrm{mL}$ & $1.17 \pm 0.07$ & $0.82 \pm 0.07$ & $<.001$ \\
\hline $\mathrm{Zn}$, mean $\pm \mathrm{SD} \mu \mathrm{g} / \mathrm{mL}$ & $2.16 \pm 0.06$ & $0.56 \pm 0.04$ & $<.001$ \\
\hline $\mathrm{Cu} / \mathrm{Zn}$, mean $\pm \mathrm{SD}$ & $0.54 \pm 0.03$ & $1.5 \pm 0.19$ & $<.001$ \\
\hline $\begin{array}{l}\mathrm{M} / \mathrm{F}=\text { male/female } \\
\mathrm{BMI}=\text { body mass index } \\
\mathrm{CRP}=\mathrm{C} \text {-reactive protein } \\
\mathrm{MDA}=\text { malonyldialdehyde } \\
\mathrm{Cu}=\text { copper } \\
\mathrm{Zn}=\text { zinc }\end{array}$ & & & \\
\hline
\end{tabular}

ics Committee approved the study, and informed consent was obtained from all subjects.

\section{Analysis}

Blood samples were collected from the antecubital veins in the sitting position between 8:00 and 10:00 AM. Following this, the collected blood samples were centrifuged for $10 \mathrm{~min}$ at room temperature. Until study analyses and other procedures, the centrifuged plasma and serum were maintained and stored at $-80^{\circ} \mathrm{C}$. A commercial enzymelinked immunosorbent assay kit (USCN Life Science, Wuhan, China) was used to evaluate telomerase levels. Serum malondialdehyde levels were measured using spectrophotometric methods assessing the level of thiobarbituric acid-reactive substances with a spectrophotometer (model 4010, Hitachi, Tokyo, Japan). Spectrophotometric measurements were then performed on the supernatant at 535 $\mathrm{nm}$. The concentration of malondialdehyde was expressed as $\mu \mathrm{mol} / \mathrm{L}$ of plasma. A Spectra AA220 flame atomic absorption spectrophotometer (Varian Pty Ltd, Victoria, Australia) was used to measure the serum concentrations of copper $(\mathrm{Cu})$ and zinc $(\mathrm{Zn})$.

\section{Statistical Analysis}

SPSS 12.0 (SPSS, Chicago, Illinois) was used for the statistical analyses. Normal distribution was assessed for continuous variables. The variables without normal distribution were analyzed by the proper non-parametric test.
Student $t$ test or the Mann-Whitney U test was used to compare continuous variables between 2 groups. In addition, the chi-square test was used to analyze categorical variables between groups. Correlation is used to evaluate relationships among variables. It can indicate only how or to what extent variables are associated with each other. The correlation coefficient measures only the degree of linear association between 2 variables. The results were expressed in $n$ and percentage or mean \pm SD. A $P$ value of $<.001$ was considered significant.

\section{Results}

The study included 87 subjects, and these subjects were divided into groups for COPD exacerbation $(n=45)$ and healthy subjects with tobacco use $(n=42)$. The groups are presented in Table 1. Subjects with COPD exacerbation (29 male, 16 female) had a mean age of $61.3 \pm 4.1 \mathrm{y}$. The control group (30 male, 12 female) had a mean age of $61.1 \pm 4.4 \mathrm{y}$. There was no difference in age and sex between the 2 groups $(P=.48, P=.85)$. The COPD exacerbation group had a mean $C$-reactive protein level of $31.33 \pm 5.81 \mathrm{mg} / \mathrm{dL}$. Subjects with COPD exacerbation had a mean $\mathrm{FEV}_{1}$ level of $0.84 \pm 0.18 \mathrm{~L}$ and a mean FVC level of $1.34 \pm 0.19 \mathrm{~L}$. The levels of $\mathrm{FEV}_{1}$ and FVC were found to be significantly lower in the COPD exacerbation group compared with the control group (Table 1). COPD subjects had a mean body mass index of $25.5 \pm 0.8 \mathrm{~kg} / \mathrm{m}^{2}$.

The level of C-reactive protein and the erythrocyte sedimentation rate were found to be significantly $(P<.001)$ 


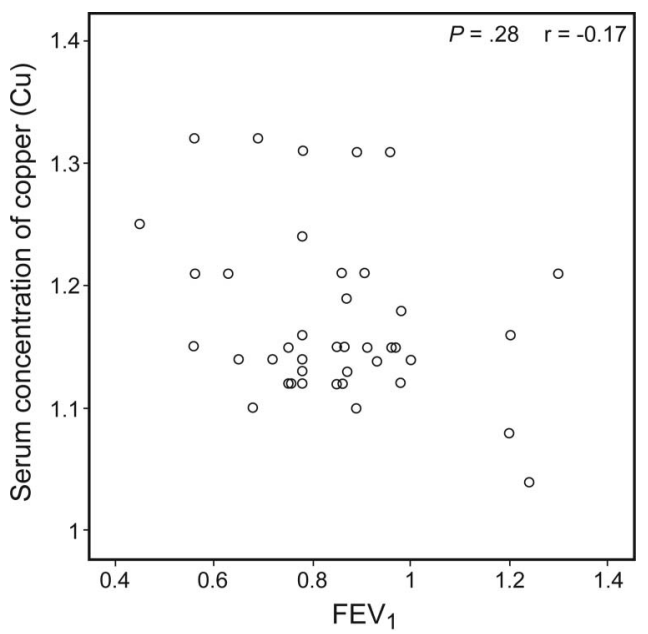

Fig. 1. Correlation of $\mathrm{FEV}_{1}$ and copper $(\mathrm{Cu})$ levels in subjects with COPD exacerbation $(P<.001)$.

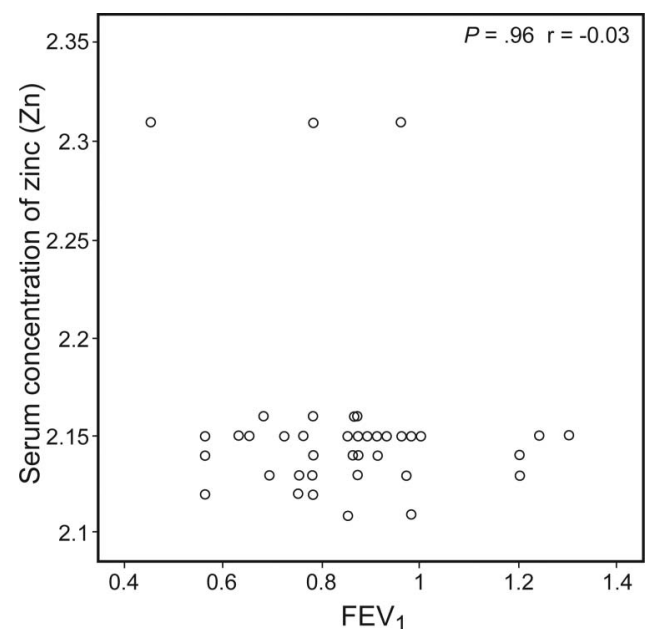

Fig. 2. Correlation of $\mathrm{FEV}_{1}$ and zinc (Zn) levels in subjects with COPD exacerbation $(P<.001)$.

higher in the COPD exacerbation group compared with the control group. The levels of telomerase, $\mathrm{Cu}, \mathrm{Zn}$, and malondialdehyde were found to be significantly $(P<.001)$ higher in the COPD exacerbation group compared with the control group (Table 1). $\mathrm{Cu}(P=.27, \mathrm{r}=-0.17), \mathrm{Zn}$ $(P=.96, \mathrm{r}=-0.03)$, and malondialdehyde $(P=.94$, $\mathrm{r}=0.01$ ) levels and $\mathrm{FEV}_{1}$ were found to be negatively correlated in the COPD exacerbation and control groups $(P<.001)$ (Figs. $1-3)$. The ratio of $\mathrm{Cu} / \mathrm{Zn}$ was found to be lower in the COPD exacerbation group compared with the control group $(P<.001)$ (Fig. 4). Malondialdehyde, $\mathrm{Cu}, \mathrm{Zn}$, and telomerase levels of the groups are shown in Figure 5.

\section{Discussion}

It is believed that oxidative stress is one of the key pathogenetic mechanisms in COPD, especially in COPD

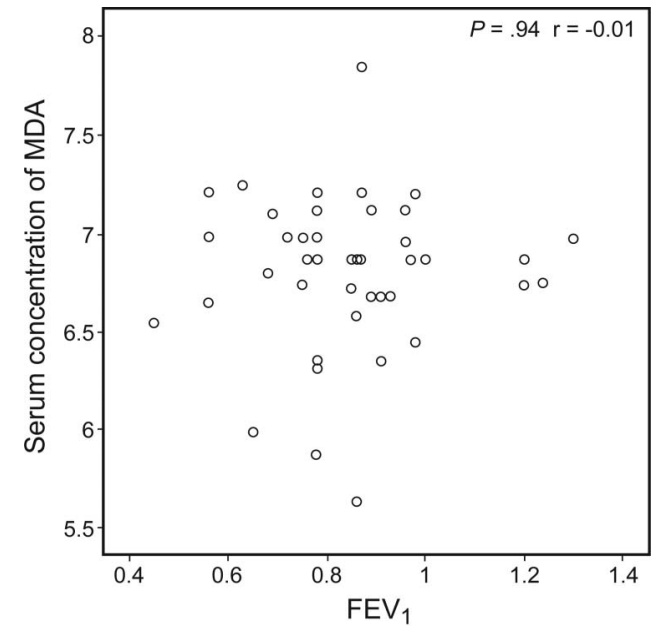

Fig. 3. Correlation of $\mathrm{FEV}_{1}$ and malondialdehyde (MDA) levels in subjects with COPD exacerbation $(P<.001)$.

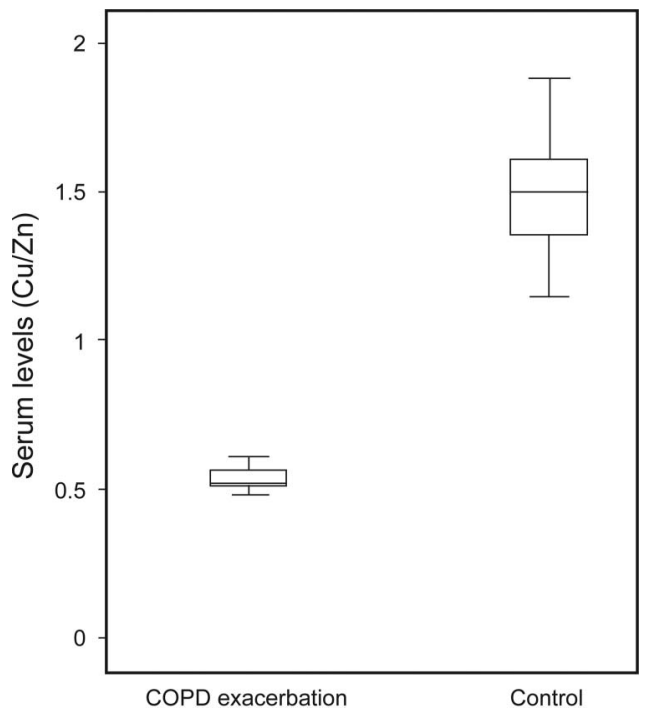

Fig. 4. Comparison of copper/zinc ( $\mathrm{Cu} / \mathrm{Zn}$ ) levels between the control group and group with COPD exacerbation. Boxes show interquartile ranges, lines in the boxes show median, and whiskers show minimum and maximum values.

exacerbation. ${ }^{17}$ In the present study, the serum levels of telomerase malondialdehyde, $\mathrm{Cu}$, and $\mathrm{Zn}$ were found to be increased in COPD subjects within the exacerbation period along with a reduced $\mathrm{Cu} / \mathrm{Zn}$ ratio. As far as we know, this is the first study that compares the role of telomerase level and $\mathrm{Cu} / \mathrm{Zn}$ ratio by especially addressing the oxidative stress and the trace element system, through the serum levels of malondialdehyde, telomerase, $\mathrm{Cu}$, and $\mathrm{Zn}$ in COPD subjects.

The increased oxidative stress in COPD subjects results from the increased oxidants existing in tobacco smoke or the increased amount of reactive oxygen species released from leukocytes, which are both present in air spaces and 


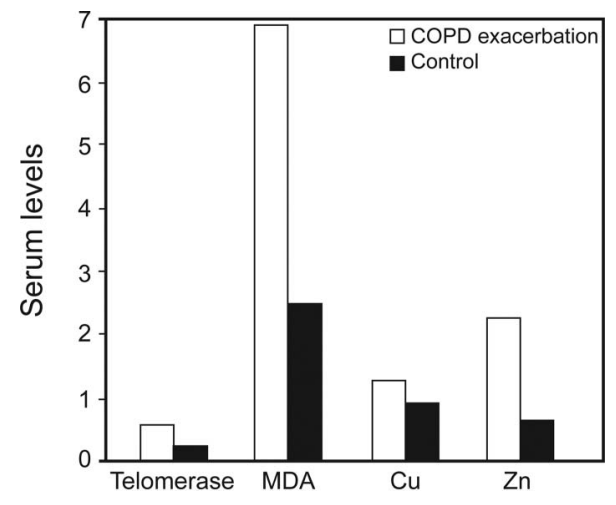

Fig. 5. Malondialdehyde (MDA), copper (Cu), zinc ( $\mathrm{Zn})$, and telomerase levels of the groups.

blood. ${ }^{18}$ Reactive oxygen species primarily target the polyunsaturated fatty acids found in the cell membranes, with an exposure to lipid peroxidation, and this can cause impaired structure and function of the cell. ${ }^{19}$ In addition, a wide range of end products (including malondialdehyde) occur as a result of the decomposition of lipid hydroperoxides. The commonly used method for an indirect measure of the increased lipid peroxidation is to measure malondialdehyde from biological samples in oxidative stress. There was an increased serum level of malondialdehyde in COPD subjects during the exacerbation period in this study. In addition, another study found a tendency for an increase in malondialdehyde levels associated with COPD subjects with smoking habits. ${ }^{20}$

Several trace elements have significant parts in the activation or inhibition of the enzymatic reactions through the competition with other elements and metalloproteins for binding sites, through the effect on the permeability of cell membranes, and through other mechanisms. These elements play significant roles in the balance between oxidants and antioxidants. Again, the hypothesis for the trace elements that they present some direct or indirect effects on the COPD process would not be irrational. ${ }^{21}$

It was reported that the trace elements' serum concentrations were found to be changed by experimental and clinical pulmonary damage. ${ }^{22,23}$ The serum concentrations of $\mathrm{Cu}$ were used as an index of pulmonary damage in rat pneumotoxicity models, whereas there were increased serum levels of $\mathrm{Cu}$ and pulmonary tissue $\mathrm{Cu} / \mathrm{Zn}$ activity in irradiated rats. ${ }^{22}$ Nevertheless, Molteni et $\mathrm{al}^{23}$ found that the serum concentrations of $\mathrm{Cu}$ and iron were within normal limits in subjects with COPD. The $\mathrm{Cu}$ level has been reported to be higher in COPD subjects compared with control groups. ${ }^{6,24}$ One study ${ }^{25}$ found significantly higher levels of $\mathrm{Cu}$ in coppersmiths compared with a control group. Another study demonstrated that there were elevated levels of $\mathrm{Zn}$ and $\mathrm{Cu}$ in sputum in suppurative and inflammatory lung disease, whereas the levels of $\mathrm{Zn}$ declined after the suppurative and inflammatory lung disease exacerbation was treated. ${ }^{26}$ Tanrikulu et $\mathrm{al}^{27}$ found increased $\mathrm{Cu}$ and $\mathrm{Zn}$ levels in the COPD exacerbation group, and $\mathrm{Cu}$ and $\mathrm{Zn}$ levels negatively correlated with $\mathrm{FEV}_{1}$ and FVC levels. In agreement with this study, we determined in our study that the levels of $\mathrm{Cu}$ and $\mathrm{Zn}$ were elevated in the COPD exacerbation group, and there was a negative correlation of the $\mathrm{Cu}$ and $\mathrm{Zn}$ levels with the $\mathrm{FEV}_{1}$ and FVC levels. Because there is an elevated amount of trace elements during exacerbation, the severity and the treatment efficacy for COPD exacerbation may be monitored through the levels and changes of these elements. The disease-related inflammation may cause the elevated levels of $\mathrm{Cu}$ and $\mathrm{Zn}$. Trace elements are probably less sensitive to the activity of protease and may be a more reliable method for measuring the inflammation of an airway. Consequently, trace element measurement can enable detection of more disorders of the airway and also provide valuable information about pulmonary inflammation in COPD-like conditions. ${ }^{27}$

Telomerase is a unique polymerase, and it synthesizes telomeric repeats. ${ }^{28,29}$ There are 2 core components of telomerase: the catalytic reverse transcriptase and the RNA component. The telomerase RNA component contains a template region that is used by the telomerase reverse transcriptase component for the addition of a new telomeric sequence onto the chromosome ends. ${ }^{30,31}$ It was reported that the mutations of telomerase had a vital part in the genetics of pulmonary conditions in studies conducted with families with idiopathic pulmonary fibrosis. ${ }^{32,33}$ Actually, the most commonly detectable defect in families with pulmonary fibrosis is the inherited mutations in the core components of telomerase, human telomerase reverse transcriptase and human telomerase RNA component, and this defect corresponds to $10-15 \%$ of all cases. ${ }^{34}$ Additionally, telomeres that are shortened are considered to be a risk factor in idiopathic pulmonary fibrosis. ${ }^{35}$ In an earlier study, ${ }^{36}$ it was also stated that the telomeres were shorter in the lungs of emphysema subjects than in unaffected persons with a similar amount of exposure to tobacco smoke. Nevertheless, there has been no investigation into the role of telomere length as a determinant of lung disease due to tobacco smoke in an animal model, which is defined genetically. The study by Houben et $\mathrm{al}^{37}$ demonstrated a significantly shorter telomere length in the leukocytes of COPD subjects compared with healthy and age-matched control subjects, and this suggests that elevated oxidative stress plays a significant role in telomere shortening. The telomerase level was found to be higher in a subject with COPD exacerbation in the present study. Although these study results do not constitute definite evidence of a direct causative relationship, we believe that telomerase may be considered as the primary marker of inflammation-related diseases (and oxidative stress) like the systemic pathophysiological process that is COPD. As 


\section{TElomerase AND COPD}

far as we know, C-reactive protein and erythrocyte sedimentation rate are the most common markers of inflammation that are often used for both evaluation and treatment of inflammatory disorders. ${ }^{38}$ Both are extremely significant biomarkers with an elevation in acute COPD exacerbation, and the present study has found that telomerase, C-reactive protein, and erythrocyte sedimentation rate are significantly higher in subjects with COPD exacerbation. This finding indicates that telomerase can be used as a beneficial parameter for the assessment of COPD exacerbation.

\section{Conclusions}

The present study is the first to investigate the level of telomerase in COPD exacerbation. The findings of the present study indicate that the impaired balance between oxidants and antioxidants and the increased level of telomerase are associated. However, there is still a need for clarification of whether the increased level of telomerase is a cause or a consequence of such imbalance, and further studies will be required.

\section{ACKNOWLEDGMENTS}

We thank Anıl Samur, a student in the Department of Biostatistics, Faculty of Medicine, Akdeniz University, for contributing to the statistical analyses of this work. We extend our appreciation to the subjects and the healthy volunteers who generously collaborated in this study.

\section{REFERENCES}

1. Aldonyte R, Jansson L, Piitulainen E, Janciauskiene S. Circulating monocytes from healthy individuals and COPD patients. Respir Res 2003;4:11.

2. Izquierdo JL, Barcina C, Jiménez J, Muñoz M, Leal M. Study of the burden on patients with chronic obstructive pulmonary disease. Int J Clin Pract 2009;63(1):87-97.

3. Cao Z, Ong KC, Eng P, Tan WC, Ng TP. Frequent hospital readmissions for acute exacerbation of COPD and their associated factors. Respirology 2006;11(2):188-195.

4. Celli BR, MacNee W. Standards for the diagnosis and treatment of patients with COPD: a summary of the ATS/ERS Task Force. Eur Respir J 2004;23(6):932-946.

5. Van Helvoort HA, Heijdra YF, Thijs HM, Viña J, Wanten GJ, Dekhuijzen PN. Exercise induced systemic effects in musclewasted patients with COPD. Med Sci Sports Exerc 2006;38(9):1543-1552.

6. Isik B, Isik RS, Ceylan A, Calik O. Trace elements and oxidative stress in chronic obstructive pulmonary disease. Saudi Med J 2005; 26(12):1882-1885.

7. Tarry-Adkins JL, Ozanne SE, Norden A, Cherif H, Hales CN. Lower antioxidant capacity and elevated p 53 and $\mathrm{p} 21$ may be a link between gender disparity in renal telomere shortening, albuminuria, and longevity. Am J Physiol Renal Physiol 2006;290(2):F509-F516.

8. Tchirkov A, Lansdorp PM. Role of oxidative stress in telomere shortening in cultured fibroblasts from normal individuals and patients with ataxia-telangiectasia. Hum Mol Genet 2003;12(3):227232.

9. von Zglinicki T. Oxidative stress shortens telomeres. Trends Biochem Sci 2002;27(7):339-344.
10. Blackburn EH. Switching and signaling at the telomere. Cell 2001 106(6):661-673.

11. von Zglinicki T. Telomeres and replicative senescence: is it only length that counts? Cancer Lett 2001;168(2):111-116.

12. Joosten SA, van Ham V, Nolan CE, Borrias MC, Jardine AG, Shiels PG, et al. Telomere shortening and cellular senescence. Am J Pathol 2003;162(4):1305-1312.

13. Makarov VL, Hirose Y, Langmore JP. Long G tails at both ends of human chromosomes suggest a $\mathrm{C}$ strand degradation mechanism for telomere shortening. Cell 1997;88(5):657-666.

14. Serra V, Grune T, Sitte N, Saretzki G, von Zglinicki T. Telomere length as a marker of oxidative stress in primary human fibroblast cultures. Ann N Y Acad Sci 2000;908:327-330.

15. Rabe KF, Hurd S, Anzueto A, Barnes PJ, Buist SA, Calverley, P, et al. Global strategy for the diagnosis, management, and prevention of chronic obstructive pulmonary disease: GOLD executive summary. Am J Respir Crit Care Med 2007;176(6):532-555.

16. Miller MR, Hankinson J, Brusasco V, Burgos F, Casaburi R, Coates A, et al. Standardisation of spirometry. Eur Respir J 2005;26(2):319338.

17. Tuder RM, Petrache I. Pathogenesis of chronic obstructive pulmonary disease. J Clin Invest 2012;122(8):2749-2755.

18. Macnee W, Rahman I. Oxidants and antioxidants as therapeutic targets in chronic obstructive pulmonary disease. Am J Respir Crit Care Med 1999;160(5 Pt 2):S58-S65.

19. Floyd RA. Role of oxygen free radicals in carcinogenesis and brain ischemia. FASEB J 1990;4(9):2587-2597.

20. Cristóvão C, Cristóvão L, Nogueira F, Bicho M. Evaluation of the oxidant and antioxidant balance in the pathogenesis of chronic obstructive pulmonary disease. Rev Port Pneumol 2013;19(2):70-75.

21. El-Attar M, Said M, El-Assal G, Sabry NA, Omar E, Ashour L. Serum trace element levels in COPD patient: the relation between trace element supplementation and period of mechanical ventilation in a randomized controlled trial. Respirology 2009;14(8):1180-1187.

22. Ward WF, Molteni A, Ts'ao C, Ischiropoulos H. Serum copper concentration as an index of experimental lung injury. Adv Exp Med Biol 1989;258:287-302.

23. Molteni A, Ward WF, Kim YT, Shetty R, Brizio-Molteni L, Giura R, et al. Serum copper concentration as an index of clinical lung injury. Adv Exp Med Biol 1989;258:273-285.

24. Karadag F, Cildag O, Altinisik M, Kozaci LD, Kiter G, Altun C. Trace elements as a component of oxidative stress in COPD. Respirology 2004;9(1):33-37.

25. Dagli CE, Tanrikulu AC, Koksal N, Abakay A, Gelen ME, Demirpolat $\mathrm{G}$, et al. Interstitial lung disease in coppersmiths in high serum copper levels. Biol Trace Elem Res 2010;137(1):63-68.

26. Gray RD, Duncan A, Noble D, Imrie M, O’Reilly DS, Innes JA, et al. Sputum trace metals are biomarkers of inflammatory and suppurative lung disease. Chest 2010;137(3):635-641.

27. Tanrikulu AC, Abakay A, Evliyaoglu O, Palanci Y. Coenzyme Q10, copper, zinc, and lipid peroxidation levels in serum of patients with chronic obstructive pulmonary disease. Biol Trace Elem Res 2011; 143(2):659-667.

28. Greider CW, Blackburn EH. Identification of a specific telomere terminal transferase activity in tetrahymena extracts. Cell $1985 ; 43$ (2 Pt 1):405-413

29. Greider CW, Blackburn EH. The telomere terminal transferase of tetrahymena is a ribonucleoprotein enzyme with two kinds of primer specificity. Cell 1987;51(6):887-898.

30. Greider CW, Blackburn EH. A telomeric sequence in the MA of tetrahymena telomerase required for telomere repeat synthesis. Nature 1989;337(6205):331-337. 


\section{Telomerase AND COPD}

31. Feng J, Funk WD, Wang SS, Weinrich SL, Avilion AA, Chiu CP, et al. The RNA component of human telomerase. Science 1995; 269(5228):1236-1241.

32. Armanios MY, Chen JJ, Cogan JD, Alder JK, Ingersoll RG, Markin $\mathrm{C}$, et al. Telomerase mutations in families with idiopathic pulmonary fibrosis. N Engl J Med 2007;356(13):1317-1326.

33. Tsakiri KD, Cronkhite JT, Kuan PJ, Xing C, Raghu G, Weissler JC, et al. Adult-onset pulmonary fibrosis caused by mutations in telomerase. Proc Natl Acad Sci USA 2007;104(18):7552-7557.

34. Armanios M. Syndromes of telomere shortening. Annu Rev Genomics Hum Genet 2009;10:45-61.
35. Alder JK, Chen JJ, Lancaster L, Danoff S, Su SC, Cogan JD, et al. Short telomeres are a risk factor for idiopathic pulmonary fibrosis. Proc Natl Acad Sci USA 2008;105(35):13051-13056.

36. Tsuji T, Aoshiba K, Nagai A. Alveolar cell senescence in patients with pulmonary emphysema. Am J Respir Crit Care Med 2006; 174(8):886-893.

37. Houben JM, Mercken EM, Ketelslegers HB, Bast A, Wouters EF, Hageman GJ, et al. Telomere shortening in chronic obstructive pulmonary disease. Respir Med 2009;103(2):230-236.

38. Sin DD, Man SF. Biomarkers in COPD: are we there yet? Chest 2008;133(6):1296-1298. 